\title{
The Indian Institute of Science
}

\section{Quinguennial Reviewing Committee}

$\mathrm{T}$ HE report of the second quinquennial reviewing committee of the Indian Institute of Science, Bangalore, presented to the secretary of the Government of India toward the end of March last, has now been published (Bangalore: Mysore Residency Press). The committee was appointed by H.E. the Viceroy of India two months earlier, and its members were: Sir James Irvine, principal and vice-chancellor, University of St. Andrews (chairman) ; the late Dr. A. H. Mackenzie, pro-vice-chancellor, Osmania University, Hyderabad; and Dr. S. S. Bhatnagar, professor of chemistry in the Punjab University, with Mr. F. F. C. Edmonds, inspector of schools, Coorg and Bangalore (secretary).

The terms of reference to the Committee were :

"To review the working of the Institute with special reference to the purposes for which it was founded and, if any changes are considered desirable in the organization or activities of the Institute for the better achievement of these purposes, to make recommendations accordingly, but with due regard to the Institute's actual or reasonably augmentable financial resources."

The subjoined extracts are from the report of the Committee :

We have felt compelled to consider the whole question of the aims and objects of the. Institute as, during a period of unusually rapid change, it is more than ever necessary to secure that the policy pursued is consistent with the wishes of the Founder and of the contributing bodies. We may at once express the view that, as a first consideration, the province and purpose of the Institute must be defined in more precise terms than at present, and that such a definition should be adopted officially both by the Council of the Institute and by the Government of India. Only in this way can the aims and objects of the Institute be placed beyond individual and fluctuating interpretations; in the absence of such definition, no continuous policy can be developed.

It may be admitted that the purposes for which the Institute was created have never been clearly defined, but this is in no sense a reflection on those who founded it or who have since administered its affairs. The Founder, the late Mr. J. N. Tata, was a public-spirited and enlightened benefactor who initially envisaged a scheme for creating an Imperial Teaching University the activities of which were to be focused in three main departments, viz, a Scientific and Technical Department, a Medical Department, and a Philosophical and Educational Department. Even with the generous support offered by Mr. Tata, so comprehensive a project was beyond realization, and the idea eventually took shape that the new foundation should be a Research Institute rather than a University.

Later the Government of India, with the concurrence of the heirs and executors of Mr. J. N. Tata, defined the Scheme for the Administration of the Institute as follows:

"The object of the Institute shall be to establish Chairs and Lectureships in Science and Arts especially with a view to the promotion of original investigations in all branches of knowledge and their utilization for the benefit of India, and to provide and to assist in the provision of suitable libraries, laboratories, and all necessary appliances."

No doubt with the laudable intention of securing a measure of elasticity and reasonable freedom to meet changing conditions, the above statement of purposes was drawn up in general terms, but nevertheless the intention is clearly revealed. According to the scheme as approved, the main objective of the Institute is to promote original scientific investigations and to facilitate the utilization of knowledge "for the benefit of India". Professorships and lectureships, offices traditionally associated with University teaching, are certainly envisaged, but in this case these offices are provided for a specific purpose, viz., the equipping of students for research.

In our opinion, the phrase "the benefit of India" strikes the keynote of the policy to be followed by the Institute. Admittedly there are many ways in which a research institution may operate for the benefit of a country and it is owing to the varying interpretations placed on this critical phrase that differences of opinion have since arisen. It may be argued with good reason that the prosecution in India of research of high merit is a benefit to the country through the prestige it confers; similarly the provision of a steady succession of young men whose minds have been developed through the dis. cipline of research in pure science is another result which comes within the compass of the phrase "the benefit of India". But, whilst in full agreement with such arguments, we believe that the initial conception of the founder was that the activities of the Institute should be devoted primarily to securing for India the material benefits expected to follow from the close association of scientific research with the industries of the country.

We are fully alive to the advantages and the cultural and material benefits which accrue from fundamental scientific work; equally we recognize that there is no conflict between pure and applied research which can be, and ought to be, prosecuted side by side to their mutual advantage. We are chiefly concerned with the problem as to which of these complementary activities should carry the greater emphasis, and we hold strongly the opinion that, in accordance with the wishes of the Founder, this emphasis should be laid on the applications of scientific research to industry. Accordingly, our first recommendation is that Clause 3 in the Regulations be amended to read as follows:

"The object of the Institute shall be to establish Chairs in Science and Arts for the purpose of pro. viding advanced instruction and conducting original investigations in all branches of knowledge and particularly in such branches of knowledge as are likely to promote the material and industrial welfare of India ; to provide suitable libraries, laboratories, and equipment; and to co-operate as far as possible with such recognized institutions as exist or are founded in future for cognate objects in India." 
The adoption of the above regulation will remove ambiguity as to the purposes of the Institute, will enable a continuous policy to be followed, and will inspire confidence in the bodies which assist its finances. As will appear later in this Report, we do not recommend the curtailment of fundamental scientific research or the abolition of teaching; but in terms of the regulation now proposed, teaching (except in the case of electrical technology which stands in a special position) should be confined to preparing workers as investigators, and, while research in pure science should continue to be an approved purpose, the major part of the resources of the Institute should be applied to those investigations which are likely to be of direct benefit to industry in India.

The evidence before us shows that in some quarters it is tacitly assumed that the Institute should be capable of searching for and selecting industrial problems, of solving these problems in the laboratory, and finally of applying the results on a technical scale. Such an attitude of mind is by no means confined to India, and so long as it is maintained, the Institute will remain the target of uninformed criticism. It must be remembered that, judged by the standards of modern research organizations in Europe and America, the Institute is small and has to work within a comparatively narrow income. But even the largest and best endowed research organizations can provide only a limited service to industry, in the sense that while they may succeed in winning the new knowledge necessary to solve an industrial problem, they are rarely capable of translating laboratory results into terms of technical practice. Different types of mind and experience as well as different equipment are necessary to bridge the gap between theory and practice. In short, the correlation of science and industry demands, as a rule, three types of men, viz., (a) those who find the problem, (b) those who unfold the new knowledge necessary to solve it, and (c) those who apply the results. The corresponding qualities and knowledge are rarely combined in the same types of individual or in the same institution.

Taking into account the restrictions imposed on the Institute by its size, its income, and its geographical situation, it is essential to relieve the staff of the sole responsibility for finding industrial problems for investigation. These problems should be submitted to the Institute by some responsible body capable of collecting proposals from India as a whole, and of sifting them so as to exclude merely routine inquiries (for which other agencies are available) and suggestions which are too unwieldy to be handled by the comparatively small number of workers available at Bangalore. The initiation of problems might well be undertaken by such bodies as- -

The Industrial Intelligence and Research Bureau, The Imperial Council of Agricultural Research, and Departments of Industries.

Co-operation with bodies such as those mentioned above will enable the Institute to keep in constant touch with the industrial needs of India.

Suggestions for research initiated in the above way would be received in the ordinary course of business by the Registrar and would be submitted by him to the Senate which, in turn, would allocate the problem to the appropriate department or departments. In this way, each inquiry would receive the benefit of several expert opinions, a team spirit would be fostered, and the departments of the Institute would stand in less danger than at present of intellectual isolation. To make this proposal effective will demand something more than merely formal acquiescence on the part of all concerned. The active prosecution of applied research should be regarded as a duty, willingly undertaken with the certain knowledge that the more energetically this duty is fulfilled, the less scientific prominence becomes attached to the workers themselves. Few publications are likely to result from such research work, but this need not be deplored if in the end the Institute is made to play the part for which it was created. Above all, it will be necessary to develop in members of the Institute the idea that there is no loss of scientific dignity in directing scientific research to the service of man.

\section{Conclusion}

Throughout our inquiry and in compiling our Report we have been actuated by more than a desire to rectify an unhappy situation. It has been our earnest endeavour to make suggestions, conceived in a spirit of impartiality, which may help the Institute to attain a position where, without challenge, it will operate for "the benefit of India". Within the framework of our scheme and free from the distractions of routine administration, the Director may devote his full powers to fundamental researches in Physics which must redound to the fame of the Institute as a home of intellectual effort. Equally, the Professors in other departments are placed in a position which will enable them to bring their best energies to bear on research problems affecting the industrial welfare of India, and to equipping students to play their part in the application of such work. With improved status, a greater security of tenure, and a clearer prescription of their duty, there is every reason to believe that the Professors will render this service in a happier and more helpful atmosphere.

As we foresee the effect of our proposals, the Institute in the future may be regarded as divisible into three sections each with its special sphere of activity, viz., (a) Physical and Mathematical Sciences in which the research work will continue to be primarily of a fundamental nature with an allegiance to the intellectual rather than to the industrial aspects of life, (b) Chemical Sciences which will be called upon to carry the main responsibility for applied research while not neglecting original work of a more academic type, and (c) Engineering Sciences where the duties for the time being will be in part instruc. tional and in part investigatory. We have suggested that these sections be granted a reasonable measure of autonomy, but they will not be isolated units, for they will find a common meeting place in the reconstituted Senate, where their efforts to serve science and to serve India will become in the best sense co-operative.

It may be the case that our proposals are a compromise, forced upon us by circumstances, but nevertheless we believe that they represent a workable solution of existing difficulties. If given a fair trial and if operated in the right spirit, they will enable the Institute to begin its second semi-Jubilee period with renewed hope. If our scheme fails, it can only be through the clash of personalities beyond the remedy of any powers possessed by a Reviewing Committee. Some of our proposals are. far-reaching in their effect. Their full significance will be apparent only by a study of the complete text of our Report. 